ERIK CIRAVEGNA

EDITOR INVITADO

ESCUELA DE DISEÑO

FACULTAD DE ARQUITECTURA,

DISEÑO Y ESTUDIOS URBANOS

PONTIFICIA UNIVERSIDAD CATÓLICA DE CHILE SANTIAGO, CHILE

ERIK.CIRAVEGNA@UC.CL

Cómo citar: Ciravegna, E. (2020).

Repensar los envases en tiempos de crisis:

implicancias éticas y enfoque sistémico en el

Diseño de Packaging.

RChD: creación y pensamiento, 5(9), 1-6

https://doi.org/10.5354/0719-837X.2020.59536

Revista Chilena de Diseño,

RChD: creación y pensamiento

Universidad de Chile

2020, 5(9)

http://rchd.uchile.cl

\section{Repensar los envases en tiempos de crisis: implicancias éticas y enfoque sistémico en el Diseño de Packaging}

Rethinking Packages in Times of Crisis: Ethical Implications and Systemic Approach in Packaging Design

Las crisis contemporáneas: una oportunidad de cambio

El planeta vive tiempos de crisis. Crisis medioambientales, sociales y económicas, que en sus múltiples manifestaciones ponen a prueba los paradigmas actuales y obligan a reflexionar sobre los modelos vigentes de producción y consumo, y más en general, sobre nuestros estilos de vida. Los efectos devastadores del cambio climático, las protestas sociales que se han desatado a lo largo de los últimos años, y la emergencia sanitaria más reciente producida por la pandemia de Covid-19, han generado una profunda inestabilidad a nivel global, y han exacerbado las desigualdades entre ricos y pobres, entre norte y sur del mundo. Equidad e inclusión social, libertad política, igualdad económica, justicia climática, son algunas de las demandas que activistas y manifestantes están exigiendo a los distintos gobiernos para que se tomen acciones concretas y se activen procesos de cambio para enfrentar las crisis contemporáneas.

El término crisis proviene del griego krísis que significa "decisión" y del verbo kríno que significa "yo decido, separo, juzgo". Designa el momento en que se produce una ruptura, un cambio muy marcado en algo o en una situación: en una enfermedad, en la naturaleza, en la vida de una persona o una comunidad (Fernández López, s.f.). Estar en crisis significa estar en una situación conflictiva, un desequilibrio que supone una elección. Como explica Ramon Alcoberro, la palabra crisis tuvo un origen agrario, vinculada a la recogida del trigo: “[...] para un griego antiguo, la crisis es el proceso que sucede cuando se separa el grano de la paja. Es un separar analítico para quedarse solo con la parte buena o aprovechable de la cosecha. De ahí que implique una capacidad de juicio" (Alcoberro, s.f., p.ı).

La crisis, entonces, aunque constituya una situación de grave dificultad y de "enfermedad" generalizada, no necesariamente tiene un significado negativo: la crisis es una oportunidad para generar un cambio, una transformación, pues es el momento en que se necesita tomar una decisión, optar por un camino y renunciar a otro. Esta decisión ha de tomarse de un modo prudente, para tener en cuenta las consecuencias de cada alternativa. Por eso es necesario elegir de manera crítica (de kritikós, "capaz de discernir") y con criterio, otra palabra griega que aparece en este contexto (criterion, con el significado de "tribunal de justicia").

El packaging: un objeto controversial frente a las crisis Las crisis contemporáneas han llevado una vez más a cuestionar con fuerza los actuales sistemas de producción y consumo, y ponen particular énfasis en el problema de la gestión de los residuos y los costes económicos, sociales y medioambientales- asociados a los envases, 
1. Ver a tal propósito los resultados del proyecto de investigación y creación Eterno Cotidiano, desarrollado entre 2017 y 2018 por Verónica Ode y Erik Ciravegna, y financiado por el "Concurso CreArt: Fondo de Creación Artística 2016" de la Vicerrectoría de Investigación y Desarrollo-VID de la Universidad de Chile. El proyecto, en el cruce disciplinar entre diseño y artes visuales, buscaba visibilizar y concientizar sobre la huella humana dejada en nuestros entornos, al resignificar los desechos encontrados en el espacio urbano (en particular, los envases) y convertirlos, a través de la experimentación con emulsiones fotosensibles, en soportes fotográficos no convencionales. (Ode y Ciravegna, 2019) especialmente los plásticos. Un segmento importante de la opinión pública, considera el packaging como una de las principales causas de la contaminación global, la huella (Doménech Quesada, 2007) visible de la actividad humana en nuestros entornos, un símbolo de lo efímero e innecesario, la expresión tangible de los excesos de los modelos actuales. ${ }^{1}$ La controversia causada por el packaging, requiere entonces una reflexión profunda, pero sin caer en eslóganes fáciles y mensajes demagógicos, como suele ocurrir con ciertas campañas \#plasticfree o \#nopackaging. Es necesario adoptar una perspectiva crítica, es decir, separar analíticamente lo bueno de lo malo y, para retomar la metáfora agraria, quedarse finalmente "con la parte buena o aprovechable de la cosecha". Por otra parte, hay que adoptar un enfoque sistémico, que equilibra las funciones, responsabilidades e impactos de los envases en el contexto contemporáneo.

El packaging es una prótesis (Bucchetti, 1999, p. 46), una extensión artificial que sirve para proteger, conservar y mantener en buen estado los bienes de consumo durante la fase de transporte, manipulación, almacenaje, distribución y también durante la venta; asegura que una persona pueda acceder a su contenido e interactuar con él; facilita además la transmisión de información, entrega advertencias e instrucciones de uso (Ciravegna, 2017). En situaciones de catástrofes naturales o emergencias sanitarias, como la que enfrentamos actualmente por el Covid-19, el envase es una herramienta imprescindible que garantiza el acceso a recursos esenciales como agua, alimentos y medicamentos, y ayuda a prevenir la propagación de enfermedades.

El packaging, como objeto de uso y medio de comunicación, es un objeto necesario por las funciones básicas que desempeña con respecto a la protección y conservación de los productos, la comunicación de su identidad, la transmisión de información, entre otros. Sin embargo, por su carácter transitorio y corta duración, su difusión generalizada en la vida cotidiana de las personas, con un impacto significativo en la sociedad y el medio ambiente, no deja de generar controversias.

Frente a las imágenes desgarradoras de cetáceos muertos por la ingesta de residuos plásticos o aves marinas asfixiadas por bolsas y otros accesorios desechables, parece legítimo preguntarse si la eliminación total de los envases, y en particular los de plástico, puede por ejemplo resolver el problema de la contaminación de los océanos y, en general, la crisis medioambiental en la que nos encontramos. Aunque sea retóricamente convincente, el mensaje de que la eliminación de los envases puede salvar el planeta no es, en realidad, la solución a las crisis mundiales.

El packaging es ciertamente un problema, pero no el problema. En primer lugar, el sector de envases y embalajes no es el que más contamina.

Sus efectos en el medioambiente son los más visibles: lo que flota en la superficie de los océanos se ofrece más fácilmente a la merced de la opinión pública. En comparación, la industria de la moda tiene, por ejemplo, un mayor impacto en la salud y el medio ambiente (residuos químicos, micro plásticos, entre otros), así como a nivel social (explotación del trabajo en los países subdesarrollados o en desarrollo, para citar uno de los fenómenos más fuertemente criticados hoy en día). 
En segundo lugar, los datos de la primera mitad de 2020 sobre la reducción sustancial de la contaminación en las zonas que estuvieron en lockdown para contener la propagación de la pandemia por Covid-19, junto con el creciente aumento de mascarillas y guantes desechables tirados a la calle durante la reapertura poscuarentena, confirman una vez más que el problema de los residuos, el cambio climático o las injusticias sociales no es de responsabilidad de objetos inanimados como envases y embalajes, que cumplen de manera excelente las funciones para las que fueron concebidos y producidos. Las crisis han sido y son todavía una responsabilidad humana: dependen de las elecciones que como individuos y colectividad tomamos respecto a la sobrevivencia del planeta, y si estamos dispuestos a cambiar nuestros comportamientos y hábitos de vida.

\section{Hacia una corresponsabilidad ética en el Diseño de envases}

Es necesario volver a poner al centro de la reflexión una noción de responsabilidad ética o de ética de la responsabilidad, expresión introducida por el politólogo Max Weber (1919), y luego adoptada por Hans Jonas (1979) como base para definir el llamado desarrollo sostenible. La palabra ética deriva etimológicamente del término griego ethos, que significa "comportamiento". La palabra responsabilidad procede del latín respondeo y tiene el mismo origen que el verbo responder. La ética de responsabilidad se podría definir entonces como un "comportamiento capaz de responder a alguien o algo". En otras palabras, actuar con responsabilidad ética implica considerar los efectos y consecuencias de nuestros comportamientos, y es precisamente al prever dichos efectos y consecuencias que se toman las decisiones correspondientes.

Si se aplica este concepto al sector de los envases y embalajes, para hacer frente a las crisis actuales es necesario adoptar criterios éticos a lo largo del ciclo de vida de un producto, y tener en cuenta, por una parte, los impactos específicos de cada etapa del proceso y, por otro, la corresponsabilidad de todos los actores involucrados en el llamado sistema-packaging (Ciravegna, 2010, 2017): productores y transformadores de envases, empresas usuarias, instituciones, asociaciones y consorcios, entre otros, y también los usuarios finales que desempeñan un papel determinante en las fases de compra, consumo y posconsumo.

Un packaging debe entenderse como el resultado de un conjunto integrado de elecciones realizadas por la pluralidad de actores que desempeñan, cada uno, un rol específico -directo o indirecto- en su definición. Además, por su complejidad, el proyecto de un envase requiere la intervención de diferentes habilidades y la participación de múltiples disciplinas y, por ende, implica adoptar un enfoque sistémico.

Dentro de este contexto, el Diseño juega un papel relevante de dirección, mediación y síntesis proyectual: diseñar un envase significa dar forma a soluciones que sean lugar de convergencia de perspectivas, necesidades y elecciones expresadas por las distintas partes involucradas en el desarrollo de un producto (Celaschi, 2008) y las múltiples funciones del artefacto, que conectan la dimensión comunicativa a la dimensión más estrictamente prestacional y operativa. 
Innovar el packaging en tiempos de crisis

La adopción de un enfoque ético y sistémico, además de permitir una lectura más consciente y equilibrada de los impactos -positivos y negativos- de los envases en la sociedad y el medio ambiente, puede generar nuevas trayectorias de innovación para el sector de envases y embalajes. Innovación que se ha limitado en la mayoría de los casos a intervenciones orientadas a mejorar la experiencia del consumidor o a garantizar una mejor protección y conservación de los productos gracias a la evolución tecnológica.

Diseñar o rediseñar un packaging en tiempos de crisis, y con una mirada hacia un futuro más sostenible, significa cuestionar los modelos establecidos y proponer soluciones que tengan un impacto positivo en las personas y el planeta, según una perspectiva de innovación orientada al bienestar y la calidad de vida.

Es necesario repensar el sentido de lo que hacemos, pero sobre todo el por qué y el para qué lo hacemos (purpose): es lo que Simon Sinek (2009) en su teoría del Golden Circle indica como el why, que debe establecerse antes que el what (qué hacer) y el how (cómo hacerlo) de cada organización. Este tipo de innovación podría definirse como meaningful innovation (innovación significativa), en referencia al estudio Meaningful Brands (2008) de Havas Media, o como purpose-driven innovation (innovación orientada al propósito), expresión inspirada en libro de Spence Jr. y Rushing (2011). Según los autores, las organizaciones más exitosas son aquellas que han orientado su negocio a un propósito que va más allá de la ganancia económica, con el fin de lograr un cambio real, tanto dentro como fuera de la organización, y tomar acción en favor de causas relevantes de tipo social o medioambiental.

\section{Packaging y crisis: reflexiones desde la disciplina y la práctica del Diseño} En el marco del escenario antes descrito, las controversias provocadas por el packaging requieren que se reflexione, según una perspectiva crítica y un enfoque sistémico, sobre funciones, responsabilidades e impactos de este artefacto controversial en la sociedad y el medioambiente. Por esta razón se invitó a investigadores, docentes y profesionales del área del Diseño para contribuir a esta reflexión.

A este llamado respondieron distintas voces de nuestra área disciplinar, para ofrecer una variedad de enfoques que reflejan no solamente los diversos aspectos tratados en los artículos recopilado en el vol. $5 \mathrm{~N}^{\circ} 9$ de la revista $R C h D$ : creación y pensamiento - publicación científica del Departamento de Diseño de la Facultad de Arquitectura y Urbanismo de la Universidad de Chile- sino los contextos geográficos de origen de académicas y académicos que trabajan en el área del packaging. Lo anterior genera un interesante paralelo entre Europa, en particular Italia e Inglaterra, y América del Sur, con contribuciones desde Brasil y Chile.

Abre el número el artículo de Clara Giardina y Flaviano Celaschi, que desde una perspectiva sistémica analizan el rol del Diseño como mediador y articulador de valor en el sector de envases y embalajes en Italia, y a través del proyecto de un Observatorio sobre la Innovación del Packaging promueven la colaboración y la corresponsabilidad entre empresas, con miras a procesos y productos más sostenibles. 
Chiara Remondino, Cristina Marino y Paolo Tamborrini presentan estrategias y proyectos desarrollados durante la reciente crisis sanitaria. El artículo destaca especialmente la capacidad de las empresas de responder de manera proactiva y resolutiva a los desafíos de la pandemia, para resolver problemas que van más allá del diseño de un contenedor.

La contribución de Valeria Bucchetti y Francesca Casnati se enfoca en la dimensión comunicacional del packaging y sus funciones informativas, en relación con la sostenibilidad medioambiental. El texto articula su reflexión a partir de un caso de estudio desarrollado en el marco de un proyecto de investigación europeo en torno al etiquetado verde de los productos. En su artículo, Alaster Yoxall considera las funciones de uso de los envases y examina en específico la accesibilidad del packaging. Circunscribe su análisis a los comportamientos de los adultos mayores durante el confinamiento por la pandemia de Covid-19.

Desde el cono sur, Luiz Rogério Wittmann y Denise Dantas ofrecen una panorámica sobre los cambios en los hábitos de consumo en el sector de los alimentos en Brasil, durante el período que se extiende de marzo a julio de 2020, durante la emergencia sanitaria por Covid-19.

La alimentación es también el ámbito de investigación de Denisse Díaz, que desde Chile propone una reflexión en torno a la soberanía alimentaria desde la perspectiva del Diseño de packaging. Analiza algunas de las principales causas políticas, económicas y sociales que han impulsado la reconstrucción del sistema alimentario mundial, basado en la soberanía de los pueblos. En este contexto se profundiza el caso chileno como escenario de oportunidad.

El artículo de Oscar Huerta examina el ecodiseño como un instrumento de particular relevancia para reducir los impactos a lo largo del ciclo de vida de envases y embalajes, en el marco de la aplicación de la ley de Responsabilidad Extendida del Productor (REP) en Chile, de reciente promulgación, hacia la afirmación de una economía circular en el país.

Cierra el número Pilar Molina de la Maza, que reflexiona en torno a un proyecto de kits de ayuda humanitaria para contextos de emergencias en el marco de catástrofes naturales. En este caso aplicado, el Diseño juega un rol decisivo en la trasformación de un sistema complejo en una solución que simplifica la gestión, desde la eficiencia de la logística hasta el planteamiento de un cambio cultural en torno a las donaciones, para contribuir a enfrentar la crisis de forma inclusiva, digna y pertinente.

\section{Agradecimientos}

En calidad de editor invitado de este número monográfico, espero que la nueva edición de la revista $R C h D$ : creación y pensamiento constituya un aporte para la comunidad académica y permita ampliar el debate dentro de nuestra disciplina al incorporar diversas miradas en torno al Diseño de packaging frente a las crisis contemporáneas. En este sentido, quiero expresar mi agradecimiento a quiénes facilitaron la realización de este número, en especial a las autoras y los autores que hicieron posible esta publicación al enviar sus artículos, así como también al comité de pares evaluadores por su mirada crítica y compromiso. 
Asimismo, agradezco la invitación a participar en la edición de este número y la confianza depositada en mí por parte del editor general Mauricio Vico y la coeditora Pamela Gatica, que junto con las y los integrantes del equipo editorial trabajan con dedicación a la gestión de los diversos procesos de la revista. Por último, quiero destacar el apoyo de la Dirección del Departamento de Diseño y la Dirección de Investigación y Desarrollo de la Facultad de Arquitectura y Urbanismo de la Universidad de Chile, que a nivel institucional hacen posible este proyecto editorial, relevante para la comunidad del Diseño tanto local como internacional.

\section{Referencias}

Alcoberro, R. (s.f.). Crisis: una aproximación etimológica [PDF].

Jonas, H. (1979). Das Prinzip Verantwortung: Versuch einer Ethik Filosofia i Pensament Ramon Alcoberro. http://www. alcoberro.info/assets/o3_civilizacion_-etimologia.pdf

Bucchetti, V. (1999). La messa in scena del prodotto. FRANCOANGELI.

Celaschi, F. (2008). Il design come mediatore tra bisogni. En C. Germak (Ed.), L'uomo al centro del progetto (pp. 19-31). AlLEMANDI.

Ciravegna, E. (2010). La qualità del packaging. FRANCOANGELI.

Ciravegna, E. (2017). Diseño de packaging. Una aproximación sistémica a un artefacto complejo. RChD: creación y pensamiento, 2(3), 1-17. https://doi.org/10.5354/0719-837X.2017.47825

Doménech Quesada, J. L. (2007). Huella ecológica y desarrollo sostenible. AENOR (Asociación Española de Normalización y Certificación).

Fernández López, J. (s.f.). Crisis y crítico - Etimología. Hispanoteca. eu. http://www.hispanoteca.eu/Foro/ARCHIVO-Foro/ Crisis\%20y\%2ocritico\%20-\%2oEtimolog\%C3\%ADa.htm für die technologische Zivilisation. Frankfurt: Suhrkamp.

Meaningful Brands. (2008). https://www.meaningfulbrands.com/en

Ode, V., \& Ciravegna, E. (2019). Eterno Cotidiano. La fotografía experimental como medio de rescate de objetos desechados en el espacio urbano. Tsantsa. Revista De Investigaciones Artísticas, (7), 117-123.

Sinek, S. (2009). Start with Why: How Great Leaders Inspire Everyone to Take Action. New York: Portfolio/Penguin.

Spence Jr., R. M. \& Rushing, H. (2011). It's Not What You Sell, It's What You Stand For: Why Every Extraordinary Business Is Driven by Purpose. PORTFOLIO/PENGUIN.

Weber, M. (1919). Geistige Arbeit als Beruf: vier Vorträge vor dem Freistudentischen Bund; 2. Vortrag: Politik als Beruf. DUNCKER \& HUMBLOT. 